\title{
The Influence of Finely Ground Mineral Admixture (FGMA) on Efflorescence
}

\author{
Ong Ming Wei ${ }^{1}$ and Norsuzailina Mohamed $\operatorname{Sutan}^{2}$
}

\begin{abstract}
Efflorescence phenomenon on concrete is not new and found in the form of white deposits on surfaces of concrete. Incorporation of Finely Ground Mineral Admixture (FGMA) in concrete to prevent occurrence of efflorescence is based on reduction of portlandite, densified microstructure and thus enhanced watertightness. The magnitude of efflorescence in term of percentage of calcium carbonate formation of FGMA modified mortar were evaluated at water-cement ratio of $0.3,0.4$ and 0.5 with $10 \%, 20 \%$, and $30 \%$ of cement replacement by weight. The samples were tested with chemical analysis at $7,14,21,28,60$ and 90 days. The FGMA additions into mortar were comparing with ordinary mortar to evaluate enhanced performance of FGMA modified mortar toward efflorescence. The results of this experiment showed that addition of FGMA into mortar caused less formation of calcium carbonate as partial replacement of cement with certain w/c ratio and percentage of cement replacement.
\end{abstract}

Keywords: Efflorescence, Fly Ash, Silica Fume, Calcium Hydroxide, Calcium Carbonate

\section{INTRODUCTION}

$\mathrm{R}$ ESEAECHh and development on enhancing cement based system is done progressively through past decades especially on aspect of durability. The utilization of FGMA can contribute to engineering benefits, economic benefits and ecological benefits [1]. The efflorescence is not new issues in construction industry and concluded as aesthetic problems in durability aspect. It caused unpleasant aesthetic for the construction industry especially precast concrete manufacturer and concrete or mortar for decorative purpose [2]. Efflorescence is the phenomenon of salt deposits formation, usually white, on or near surface of cement product and cause changes in appearance [3]. The salts deposit usually is calcium carbonate which is cause by transport of dissolve calcium hydroxide through surface and react with carbon dioxide and thus evaporate to become salt deposits [4].The mechanism of efflorescence formation is by dissolve calcium hydroxide at surface and reacts with carbon dioxide to form calcium carbonate. Equation 1 shows the chemical reaction formation of calcium carbonate.

$$
\mathrm{Ca}(\mathrm{OH})_{2}+\mathrm{CO}_{2}+\mathrm{H}_{2} \mathrm{O} \rightarrow \mathrm{CaCO}_{3}+2 \mathrm{H}_{2} \mathrm{O}
$$

It is not water in concrete migrate to surface and entrain the calcium hydroxide. It is the calcium hydroxide diffuses up through the water-filled capillary system of the concrete to the surface and react accordance as shown in Equation 1[5]. To effectively avoid efflorescence, it can reduce the migration of calcium ions to concrete surface, reducing size of capillary and make carbonation take place below surface of concrete [6].FGMA (e.g. fly ash and silica fume) is well known of improving concrete properties in term of workability in fresh state and enhancing in strength and impermeable in hardened state [7],[8]. Fly ash and silica fume enhances concrete properties by physical mechanisms and chemical mechanisms such as reduced bleeding, provision of nucleation sites, denser packing density of solid particles and form additional calcium-silicate hydrate (CSH) [9],[10].

The purpose of the present investigation is to develop modified cement system with enhanced mechanical properties and reduce tendency of efflorescence phenomenon by introducing FGMA to alter the properties of cement based system. This research was carried out to determine influence of fly ash and silica fume on efflorescence tendency of mortar. The efficiency of FGMA incorporation in mortar against efflorescence is evaluated based on the percentage of $\mathrm{CaCO}_{3}$ formation compare to Ordinary Portland mortar.

${ }^{1}$ Ong Ming Wei is with Department of Civil Engineering, Universiti Malaysia Sarawak, 94300 Kota Samarahan, Sarawak, MALAYSIA (email: ongmingwei9999@ hotmail.com)

${ }^{2}$ Norsuzailina Mohamed Sutan is with the Faculty of Engineering, Department of Civil Engineering, Universiti Malaysia

Sarawak, 94300 Kot Samarahan, Sarawak, MALAYSIA (email: msnorsuzailina@ feng.unimas.my) 


\section{MATERIALS AND METHODS}

A. Materials and Mix Proportions

Cement used in this experiment was Ordinary Portland Cement (OPC), produced by local manufacturer, Cahaya Mata Sarawak (CMS) with specific gravity of 3.16. The fine aggregate used is river sand (dry condition) with specific gravity of 2.6. Tap water was used throughout the experiment. FGMA used is fly ash and silica fume in powdered form as cement replacement (by wt) of $10 \%, 20 \%$ and $30 \%$.

Table 1 shows the mix proportion of mortar mixtures with 10\%, 20\% and 30\% of FGMA to cement ratio at w/c ratio of $0.3,0.4$ and 0.5 . These mortar mixes were conducted with chemical analysis and evaluated in term of percentage of calcium carbonate formation in comparison to the ordinary mortar as the control.

Table 1: Mix Proportion for Mortar Samples

\begin{tabular}{|c|c|c|c|}
\hline FGMA Replacement & w/c 0.3 & w/c 0.4 & w/c 0.5 \\
\hline $0 \%$ & $1: 0.3: 1.67: 0$ & $1: 0.4: 1.67: 0$ & $1: 0.5: 1.67: 0$ \\
\hline $10 \%$ & $1: 0.3: 1.67: 0.1$ & $1: 0.4: 1.67: 0.1$ & $1: 0.5: 1.67: 0.1$ \\
\hline $20 \%$ & $1: 0.3: 1.67: 0.2$ & $1: 0.4: 1.67: 0.2$ & $1: 0.5: 1.67: 0.2$ \\
\hline $30 \%$ & $1: 0.3: 1.67: 0.3$ & $1: 0.4: 1.67: 0.3$ & $1: 0.5: 1.67: 0.3$ \\
\hline
\end{tabular}

\section{B. Curing Condition}

The mortar specimen is demoulded after 24 hours of casting and immediately added with $10 \mathrm{~mm}$ height of water at the surface. The added surface water is then left to evaporation or absorbed by specimens. The curing condition is wet curing and exposed to laboratory environment with relative humidity of $85 \%$ and temperature of $28^{\circ} \mathrm{C}$. All the specimens were subjected to tests at the end of curing period of $7,14,21,28,60$ and $90^{\text {th }}$ days after demolding.

\section{Chemical Analysis}

All mortar mixes were conducted with chemical analysis with respect to its predetermined curing period. White deposits were observed for the samples after certain period. The surfaces of samples were then grinding into powdered form. Hydrochloric Acid is added to the sample in powdered form to determine the percentage of calcium carbonate in tested amount of powdered sample. The percentage of calcium carbonate obtained was representing the amount of calcium carbonate formed at surface of mortar.

Chemical analysis was proposed as it gives a reliable quantitative measure of the percentage of calcium carbonate $\left(\mathrm{CaCO}_{3}\right)$ produce by efflorescence. The $\mathrm{CaCO}_{3}$ may form beneath the surface of concrete/ mortar. Hence, those tests to evaluate efflorescence magnitude by concrete brightness test measures may not be that accurate due to ignoring the surface beneath $\mathrm{CaCO}_{3}[6]$.

Therefore, this method of chemical analysis is preferable to be used to evaluate the percentage of $\mathrm{CaCO}_{3}$ formation in a given sample and comparable with other type of mortar samples.

\section{RESULTS AND DISCUSSION}

A. Results

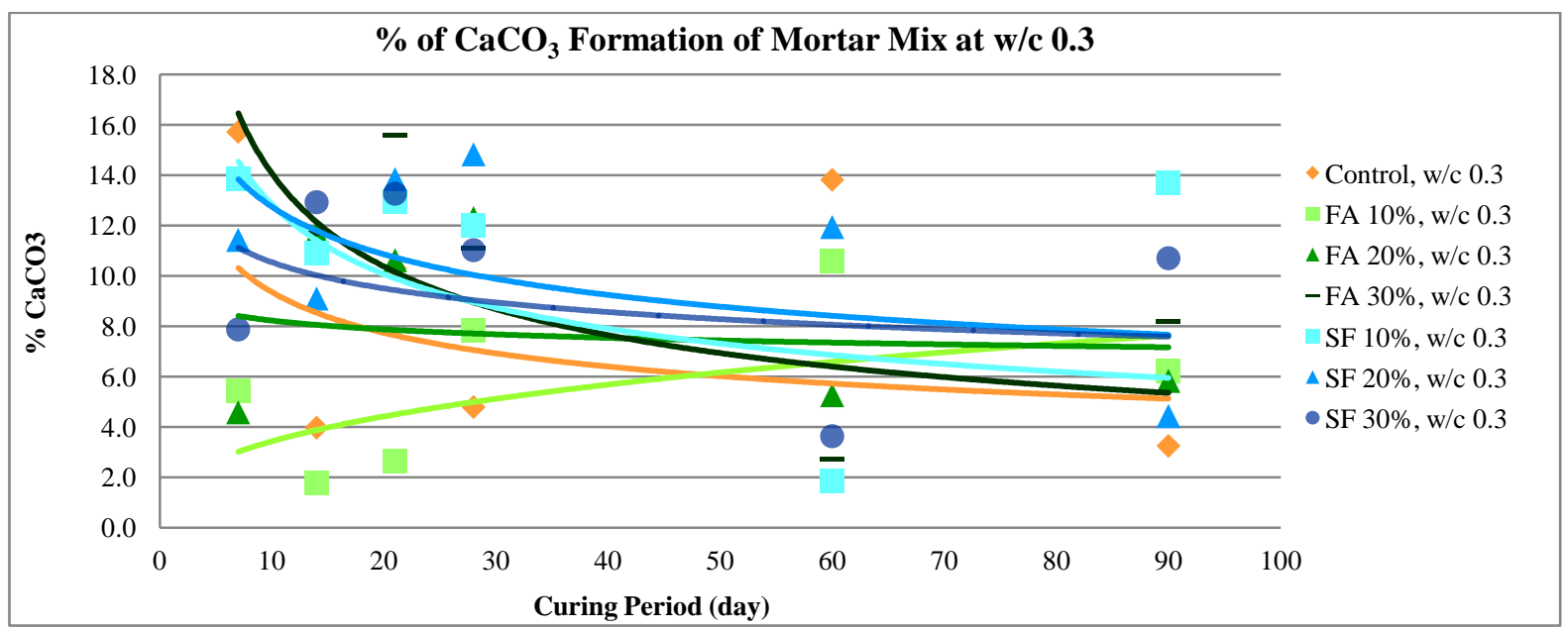

Figure 1: \% of $\mathrm{CaCO}_{3}$ versus curing periods of mortar mix at w/c 0.3 
Refer to Figure 1, it can found that most of the mortar sample exhibit higher tendency of efflorescence in term of calcium carbonate at earlier time except for FA $10 \%$ composite specimen.

Most of the mortar sample exhibit similar trend except for mortar with $10 \%$ fly ash replacement by reduction of calcium carbonate percentage as hydration process continues. Except of mortar with $10 \%$ fly ash replacement, others mortar generally exhibit poorer results in term of higher percentage of calcium carbonate formation compare to control mortar, w/c 0.3. For silica fume modified mortar, none of the mortar incorporate silica fume gives enhancement toward efflorescence.

Based on Figure 1, fly ash replacement of $10 \%$ shows lesser formation of calcium carbonate compared to control mortar, w/c 0.3 . It can be concluded that maximum replacement of fly ash is $10 \%$ at w/c 0.3 .

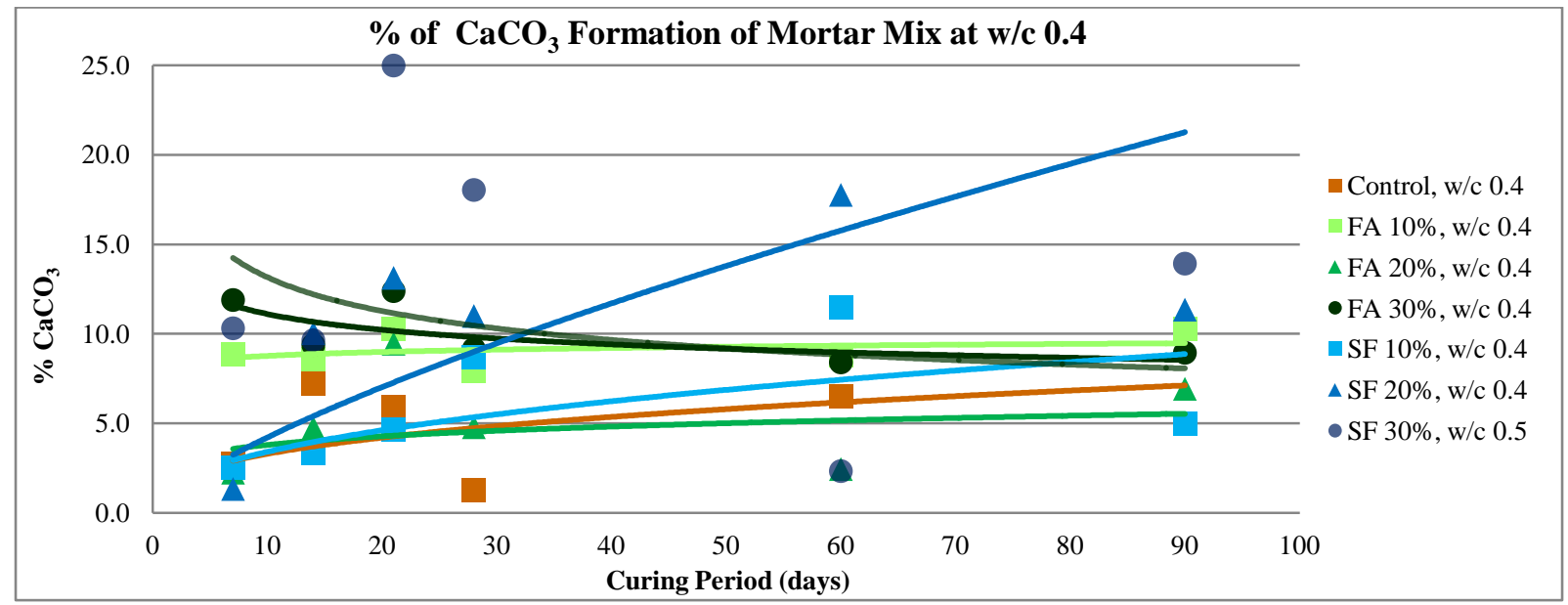

Figure 2: $\%$ of $\mathrm{CaCO}_{3}$ versus curing periods of mortar mix at w/c 0.4

By referring to Figure 2, mortar samples with replacement of 20\% FA gives most favorable result for 28 and 90 days curing period compare to other types of mortar samples at w/c ratio of 0.4 in term of percentage of $\mathrm{CaCO}_{3}$ formation. However, for mortar sample with w/c ratio of 0.4 , the poorest performance is mortar with $30 \% \mathrm{SF}, 30 \% \mathrm{FA}$ and $10 \% \mathrm{FA}$ for curing period of 28 days in descending order. However, SF 20\% mortar samples exhibit strange trend of percentage of efflorescence formation and gives very high percentage of $\mathrm{CaCO}_{3}$ at later age.

The improved performance of mortar samples after replacement by FA and SF is mortar sample with FA $20 \%$ and SF $10 \%$ at w/c 0.4. However, the mortar with SF $10 \%$ almost having same percentage of calcium carbonate formation with control mortar at w/c ratio of 0.4 . It is concluded that for mortar sets of w/c ratio of 0.4 , the only improvement in resistance toward efflorescence is mortar with replacement of $20 \% \mathrm{FA}$.

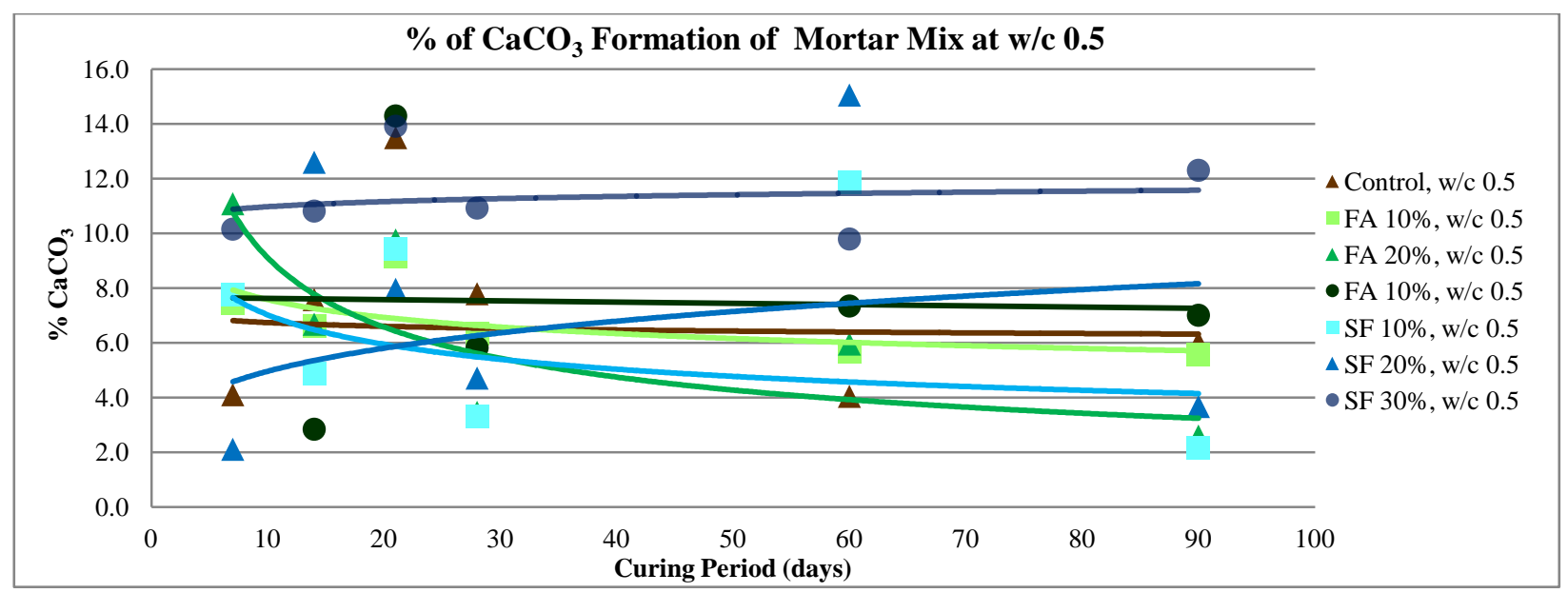

Figure 3: $\%$ of $\mathrm{CaCO}_{3}$ versus curing periods of mortar mix at w/c 0.5

By referring to Figure 3, the poorest performance is mortar sample with 30\% SF for 28 and 90 days. It is also observed that mortar samples with SF of $20 \%$ and $30 \%$ generally give high percentage of calcium carbonate for mortar sets at w/c ratio of 0.5 except mortar with $20 \% \mathrm{SF}$ which gives lowest percentage of $\mathrm{CaCO} 3$ formation at the first 7 days of curing.

The best performance of efflorescence resistance is mortar sample with $20 \%$ FA at w/c ratio of 0.5 at later age. Mortar sample with 10\% FA and 10\% SF also gives improvement compare to control mortar sample but it is not having significant improvement. It is found that, mortar samples with FGMA replacement at $30 \%$ do not enhance resistance toward efflorescence but worsen it. 


\section{B. Discussion}

The expected outcome of fly ash and silica fume addition in concrete is reduction in porosity and has better durability properties due to densified of interfacial transition zone. This may be explain by reduction in amount of calcium hydroxide as pozzolanic reaction by fly ash or silica fume particles to form additional calcium silicate hydrate gel which contribute to reduction in porosity, densified of interfacial transition zone [11],[13],[14].

This is out of the expected results whereas cement replacement by FA or SF generally should improve the resistance toward efflorescence by enhancing microstructure and reduce permeability of mortar [12].

The optimum percentage replacement of FGMA in mortar for minimum tendency and severity of efflorescence is not clear from this experiment as it varies with water-cementitious ratio. The optimum percentage replacement at w/c 0.3 for fly ash is $20 \%$ but only at earlier time. In case of w/c 0.4 , there is only mortar sample with $20 \%$ fly ash gives enhancement in properties against efflorescence. Whereby, only mortar sample with $20 \%$ fly ash and $10 \%$ silica fume gives less severity of efflorescence formation at w/c 0.5. The improvement of mortar sample at same w/c with lesser $\mathrm{CaCO}_{3}$ formation than control mortar is only for mortar sets at w/c 0.4 and w/c 0.5 .

Incorporation of FGMA increased the specific surface area of mortar and deduction in mix water due to mix water absorption on dry surface of FGMA. Especially for silica fume modified mortar, increase in water demand is significant due to high fineness of silica fume and tends to have large specific surface area [11], [13]. In this experiment, no superplasticizer was introduced for fly ash and silica fume modified mortar.

It can be concluded that the water-cement ratio does have significant effects on FGMA modified mortar against efflorescence. Apparently, the higher the content of silica fume or fly ash added and more cement is replaced; due to fixed water-cement ratio, more water is deducted from the specimen and not only that, the fly ash and silica fume in dry powder tend to absorb a certain amount of remaining water to form into cementitious properties. Thus, without sufficient of mix water, higher percentage of FGMA replacement would not gives improvement in properties of mortar due to insufficient mix water for hydration process and pozzolanic reaction to develop.

Hence, the sample becomes absolutely dry and porous surface of mortar is formed. This porous structure of mortar samples in general having high permeability and thus eases the transport of calcium hydroxide or fluid leaching out or ingress thru mortar surface. As consequence, more dissolved calcium hydroxide leaches out to surface to react with carbon dioxide to form calcium carbonate and on the other hand, more water is capable ingress thru the porous surface due to large capillary pores.

The Scanning Electron Microscope (SEM) image of the control mortar, fly ash modified mortar and silica fume modified mortar in Figure 4 and Figure 5 shows significant improvement in the microstructure in terms of pores and lesser calcium hydroxide is observed for mortar with FGMA addition as confirmed by previous findings [7][8][9].

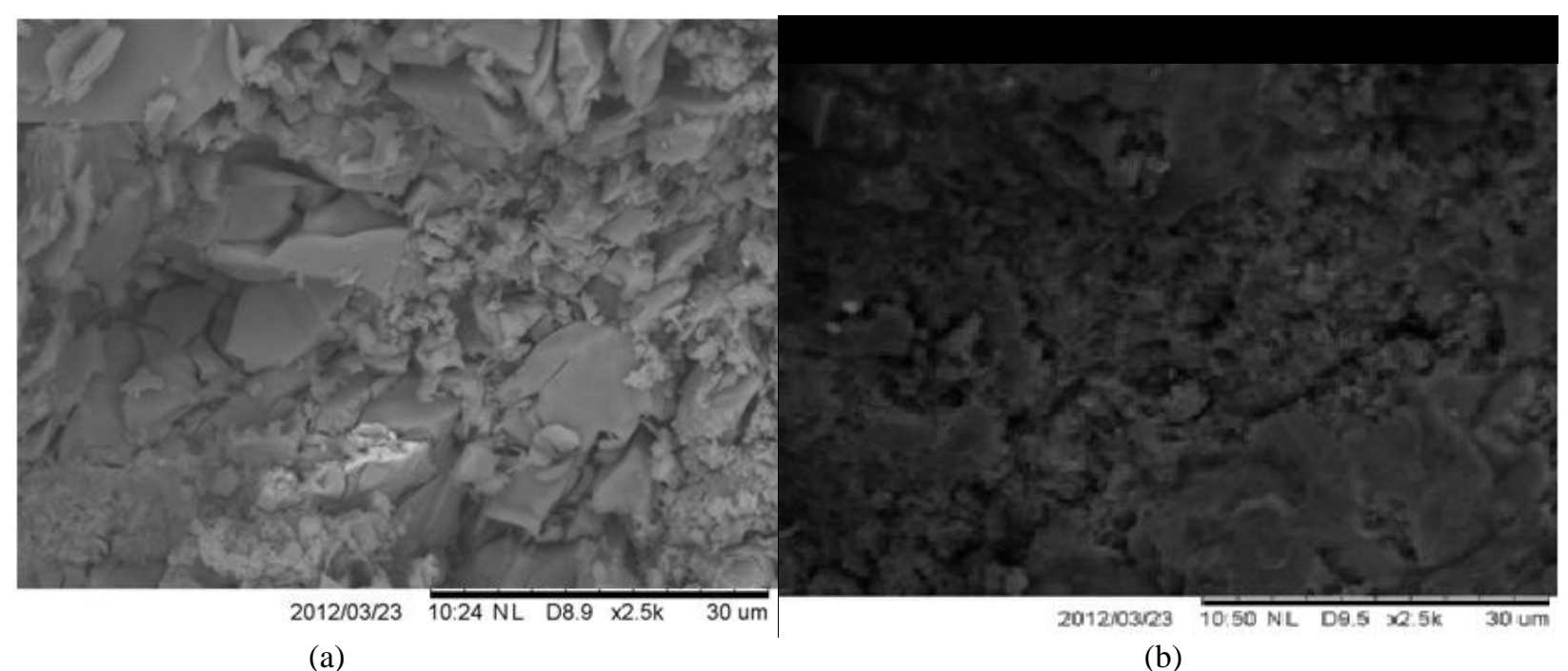

(a)

(b)

Figure 4: Scanning Electron Microscope (SEM) of control mix (a) and mortar with $20 \%$ fly ash (b) at w/c 0.5 


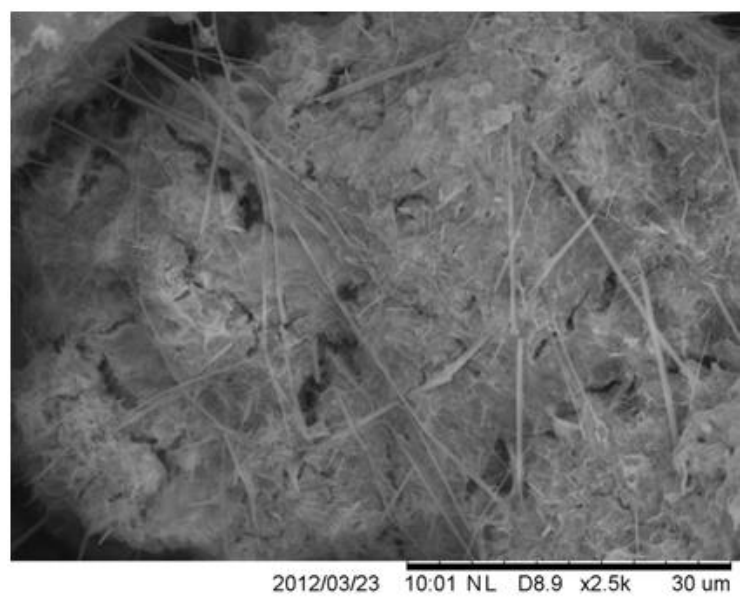

Figure 5: Scanning Electron Microscope (SEM) of mortar with 30\% silica fume at w/c 0.4

\section{CONCLUSION}

The incorporation of FGMA into mortar can reduce the severity of efflorescence by improving the properties of mortar. The employment of fly ash with cement replacement of $10 \%$ and $20 \%$ is effectively reduced severity of efflorescence whereas $30 \%$ cement replacement is not favourable in resistance to efflorescence compare to control mix. However, it is not enhanced efflorescence resistance when w/c below 0.4 for fly ash modified mortar.

The addition of silica fume as cement replacement does not enhance the resistance against efflorescence compare to control mix for w/c below than 0.5 and as well as cement replacement rate more than $10 \%$. It is obvious silica fume modified mortar require higher w/c ratio than fly ash modified mortar due to its high fineness particles. The poor performance can conclude is lack of appropriate water content for pozzolanic reaction to develop and FGMA acts as filler rather than binder.

It is recommended to test the mortar sample with higher w/c ratio to determine the true extent of pozzolanic reaction in mitigation of efflorescence. Other durability test like absorption test can use to establish relationship with efflorescence formation.

\section{ACKNOWLEDGMENT}

The authors wish to acknowledge University Malaysia Sarawak for supporting this work under the FRGS/03(04)/772/2010(53) grant. 


\section{REFERENCES}

[1]V. M. Malhotra, and P. Kumar Mehta, "Pozzolanic and cementitious materials", in Advances in Concrete Technology, Vol. 1. Taylor \& Francis, London and New York, 2004, pp. 4-5.

[2] T. Abeile, A. Keller, and R. Zurbriggen, "Efflorescence mechanism of formation and ways to prevent, Elotex AG, Swizerland.

[3] Cement Concrete \& Aggregates Australia, "Efflorescence", Cement Concrete \& Aggregates Australia, St Leonards, N.S.W., Australia

[4] J. Bensted, "Efflorescence - a visual problem on buildings", Construction Repair, vol. 8, no 1, pp. 47-49, 1994

[5] P. Kresse, "Efflorescence - mechanism of occurrence and possibilities of prevention", Concrete Plant + Precast Technology, vol. 53, pp. 160-168, 1982

[6] P. Kresse, "Coloured concrete and its enemy: efflorescence”, Chemistry and Industry, no. 4, pp. 93-95, 1989

[7] V. M. Malhotra, and P. Kumar Mehta, "Pozzolanic and cementitious materials", in Advances in Concrete Technology, Vol. 1. Taylor \& Francis, London and New York, 2004, pp. 90-91.

[8] CUR-report 144, "Fly ash as addition to concrete", CUR, Gouda, 1992, pp. 39-45.

[9] ACI Committee 234 Report, "Guide for the use of silica fume in concrete", American Concrete Insitute, ACI 234R-06, 2006.

[10] ACI Committee 232.2 Report, "Use of fly ash in concrete", American Concrete Institute, ACI 232.2R96, 1996.

[11] H. A. Toutanji and T. El-Korchi, "The influence of silica fume on the compressive strength of cement paste and mortar", Cement and Concrete Research, Vol. 25, No. 7, pp. 1591-1602, 1995

[13] S. F. U. Ahmed, Y. Ohama and K. Demura, " Comparison of mechanical properties and durability of mortar modified by silica fume and finely ground blast furnace slag", Journal of Civil Engineering, vol. 27, no. 2, 1999

[12] C. F. Christy and D. Tensing, " Efflect of Class-F fly ash as partial replacement with cement and fine aggregate in mortar”, Indian Journal of Engineering \& Materials Sciences, vol. 17, pp. 140-144, 2010

[14] D. P. Bentz and P. E. Stutzman, "Evolution of porosity and calcium hydroxide in laboratory concretes containing silica fume”, Cement and Concrete Research, Vol. 24, no. 6, pp. 1044-1050, 1994 